\title{
A Inverted C-Shape Micro Strip Patch Antenna Design for L-Band Application
}

\author{
Rajbhushan Rajput \\ RGPV \\ NIIST-Bhopal \\ Bhopal-462023, India
}

\author{
Puran Gour \\ RGPV \\ NIIST-Bhopal \\ Bhopal-462023, India
}

\author{
Rajeev Thakur \\ RGPV \\ NIIST-Bhopal \\ Bhopal-462023
}

\begin{abstract}
This paper presents an inverted C-shape microstrip patch antenna for L-band (1-2 GHz) application. The proposed antenna is suitable for dual band operation. The inverted Cshape microstrip patch is design for getting dual band. This antenna is suitable for GPS (global positioning system) carriers and satellite mobile phone application that is good for fast \& highly accurate information transformation. We observe the simulated \& validated result of proposed antenna by IE3D simulator and Agilent N9923A and to achieve a dual band. The bandwidth of lower band is $77 \mathrm{MHz}$ (freq. range $1.311-1.388 \mathrm{GHz} \&$ C.F. is $1.377 \mathrm{GHz}$ ) and upper band is $153 \mathrm{MHz}$ (freq. range $1.49-1.643 \mathrm{GHz} \&$ C.F. is $1.579 \mathrm{GHz}$ ) with $-10 \mathrm{~dB}$ return loss and $3.04 \& 3.12 \mathrm{dBi}$ gain for lower and upper band. The maximum radiating efficiency of designed antenna is $99 \%$ and directivity is $4.6 \mathrm{dBi}$
\end{abstract}

\section{Keywords}

IE3D simulator, dual-band, bandwidth, gain

\section{INTRODUCTION}

In the recent year the wireless communication system is growth very fast, the no. of device are use in this system. For improvement the performance of wireless communication system and satellite mobile phone application the multi band and wide band antenna will require to design. For high accurate $\&$ fast data, voice, video and multimedia information transformation, microstrip patch antenna is design due to this light weight and low profile. For Bluetooth \& WLAN applications U-slot patch antenna is design [1] along with modified Jerusalem cross elements using dual-band frequency selective surface. The no. of features are integrated into a single communication device for different operation, so for this reason the multiband and wide (DCS/PCS/UMTS/GSM/UMTS/Wi-MAX) band antenna is design [2]-[9] by different shape of patch and polarization techniques are use and improvement of antenna performance different type slots are cut in ground plane [10]-[12]. For reducing the size of antenna the substrate is integrated on irregular ground [13], by this structure patch is loading with capacitive and inductive. For microwave radiometry system the microstrip patch antenna is design [14].

In this paper we are design inverted $\mathrm{C}$-shape microstrip patch antenna for L-band application. The microstrip patch antenna design process is very easy and it is suitable for desired operation due to this low profile and lower coast of fabrication. That antenna is designed for GPS (global positioning system) carriers and satellite mobile phone application. The inverted $\mathrm{C}$-shape patch is design for getting dual band and improvement of antenna performance. The FR4 substrate is use and probe feed is use for feeding. We observe the simulation result and we get a dual band with $-10 \mathrm{~dB}$ return losses. The other use of designed antenna in T.V. broadcasting, microwave oven, microwave communication, mobile phone, wireless LAN, Bluetooth.

\section{ANTENNA CONFIGURATION AND DESIGN APPROCH \\ 2.1 Antenna without slots cut in ground plane}

Figure-1 shows the configuration of the presented inverted Cshape microstrip patch antenna. This antenna is designed for $2 \mathrm{GHz}$ frequency range operation. The FR4 $\left(\varepsilon_{\mathrm{r}}=4.3\right)$ substrate is used and its thickness is $1.5 \mathrm{~mm}$ along with 0.02 loss tangent. The basic structure and optimized design dimension of proposed antenna are shown in Table-1. The total dimension of design antenna is $44.88 \mathrm{~mm}$ (length) $\times 55.07 \mathrm{~mm}$ (width) $\times 1.5 \mathrm{~mm}$ (thickness).

The inverted c-shape is design in patch for getting dual band, this is shown in Figure-1 (a) and Figure-1 (b) shows the top view of designed ground plane. The front view of design antenna is shown in Figure-1 (c). And for feeding of this antenna the probe feed technique is use. The linear and circular polarization technique is used to improve the performance of designed antenna.

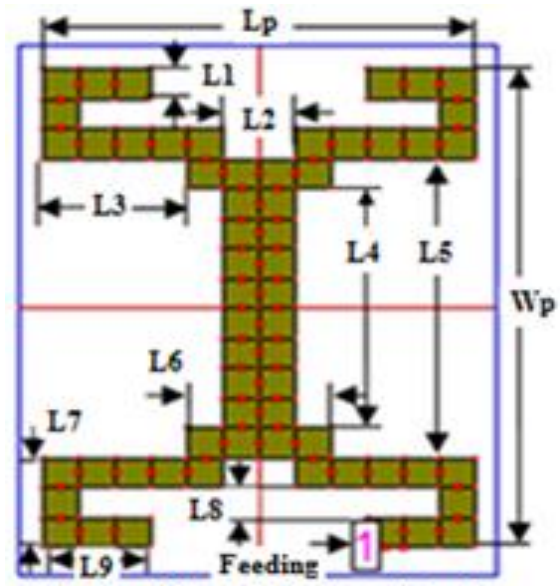

(a) Top View of Designed Patch 


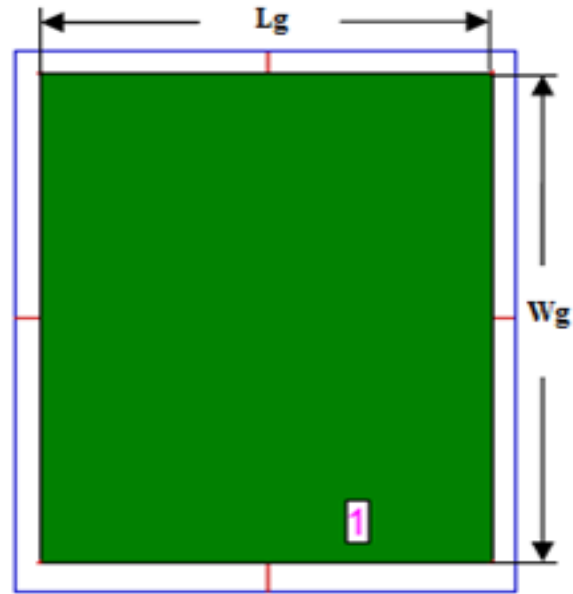

(b) Top View of Designed Ground Plane

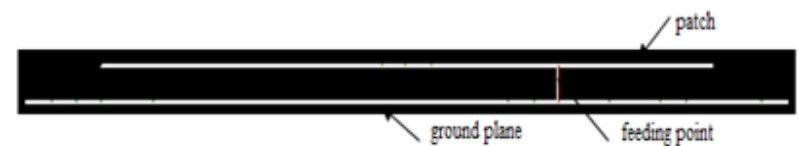

(c) Front view of designed antenna

Figure-1 Geometry of design antenna element. (a) Top View of Designed Patch. (b) Top View of Ground Plane. (c) Front View of Designed Antenna

Table-1 structure and optimized dimension of proposed antenna

\begin{tabular}{|c|c|c|c|}
\hline parameter & $\begin{array}{c}\text { Length (in } \\
\text { mm) }\end{array}$ & parameter & $\begin{array}{c}\text { Length (in } \\
\text { mm) }\end{array}$ \\
\hline Lg & 44.88 & L1 & 3 \\
\hline Wg & 55.07 & L2 & 6 \\
\hline Lp & 35.88 & L3 & 12 \\
\hline Wp & 46.07 & L4 & 24 \\
\hline $\mathbf{H}$ & 1.5 & L5 & 30 \\
\hline $\begin{array}{c}\text { Feeding } \\
\text { F(x,y) }\end{array}$ & $\begin{array}{c}\text { F(8.91,-- } \\
23.04)\end{array}$ & L6 & 12 \\
\hline & & L7 & 9 \\
\hline & & L8 & 3 \\
\hline & & L9 & 9 \\
\hline
\end{tabular}

\section{SIMULATION AND RESULT}

Figure-2, 3, 4 shows the simulated result of designed antenna by using the IE3D simulator. The Figure-2(a) shows the simulated return loss of the designed antenna. In this Figure we observe the result and we get two frequency band along with $-10 \mathrm{~dB}$ return losses .We achieve a lower band at 1.337 $\mathrm{GHz}$ center frequency and upper band at $1.579 \mathrm{GHz}$ center frequency. The bandwidth of designed antenna based on VSWR $<2$, the lower band bandwidth is $77 \mathrm{MHz}$ (freq. range $1.311-1.388 \mathrm{GHz}$ ) and the upper band bandwidth is $153 \mathrm{MHz}$ (freq. range 1.49-1.643GHz).

The Figure-2(b) shows the simulated gain of designed antenna. In this Figure we observe the result and get $3.04 \mathrm{dBi}$ $\& 3.12 \mathrm{dBi}$ gain for lower and upper band. Figure-2(c) shows the simulated directivity of designed antenna, we get max. Directivity is $4.6 \mathrm{dBi}$. Figure-2(d) shows the simulated antenna efficiency of designed antenna and we get the max. Antenna Efficiency is $98.75 \%$. Figure (e) shows the simulated radiating efficiency of designed antenna, we get max. Radiating efficiency is $99 \%$.

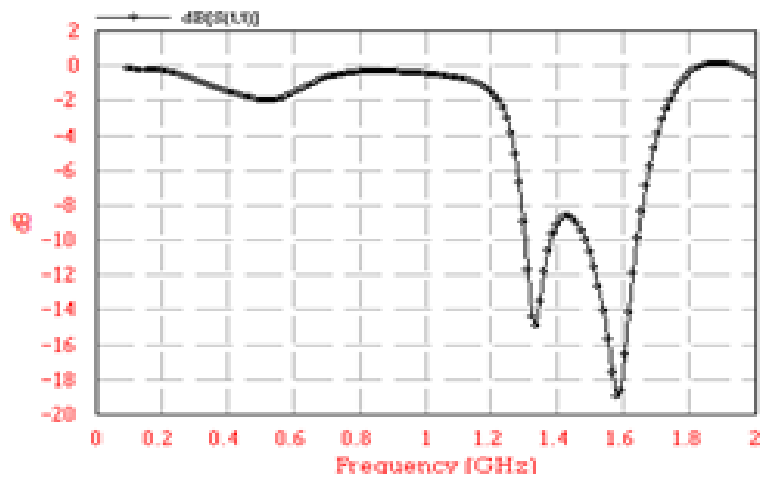

(a) Simulated Return Loss of Designed Antenna

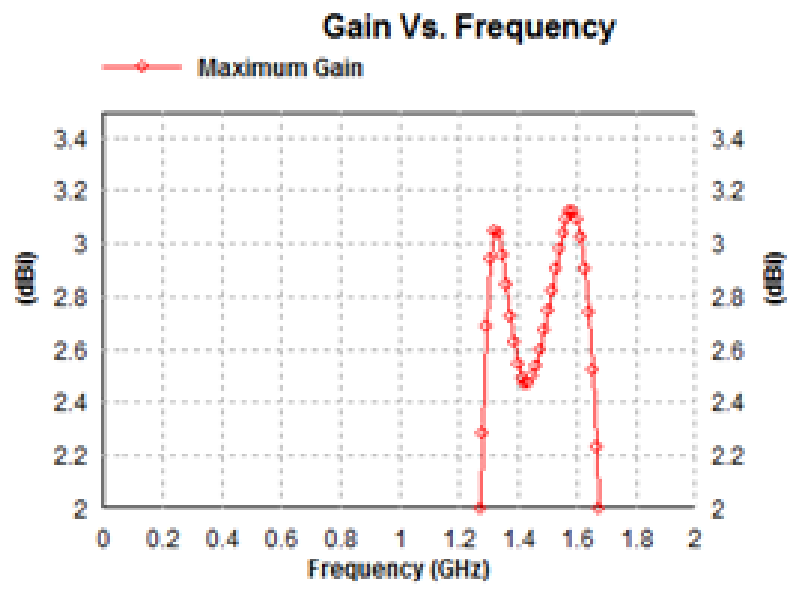

(b) Simulated Gain of Designed Antenna

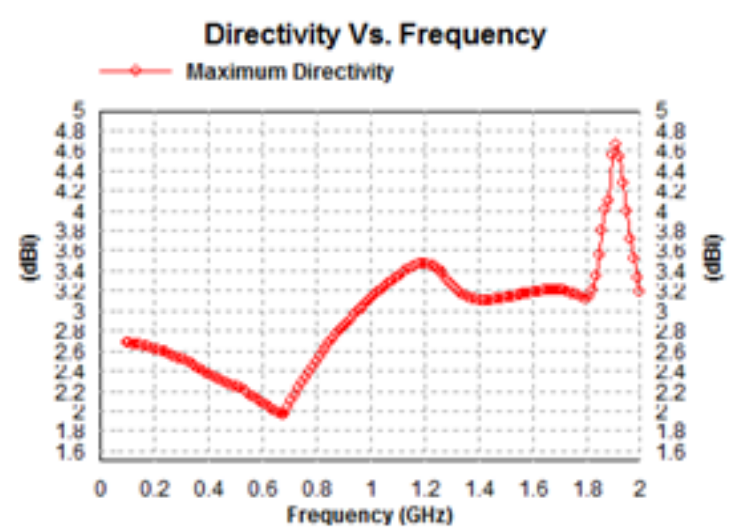

(c) Simulated Directivity of Designed Antenna

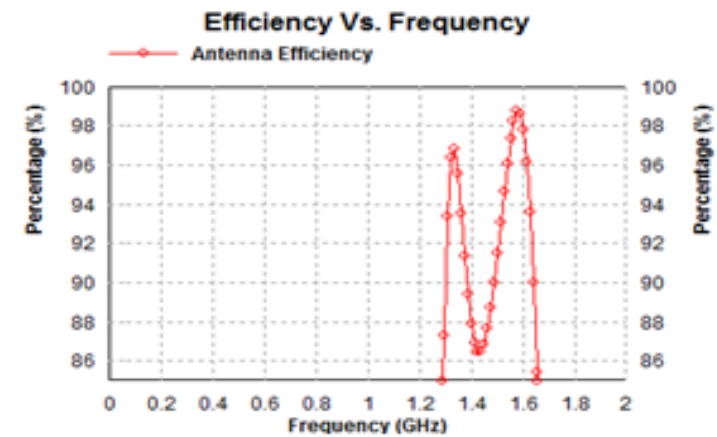

(d) Simulated Antenna Efficiency of Designed Antenna 


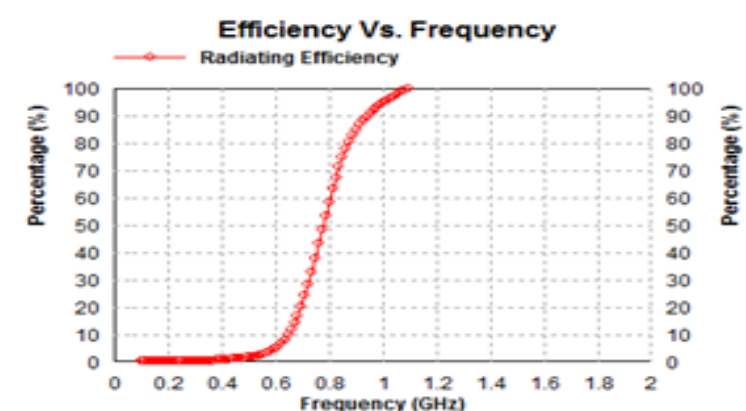

(e) Simulated Radiating Efficiency of Designed Antenna

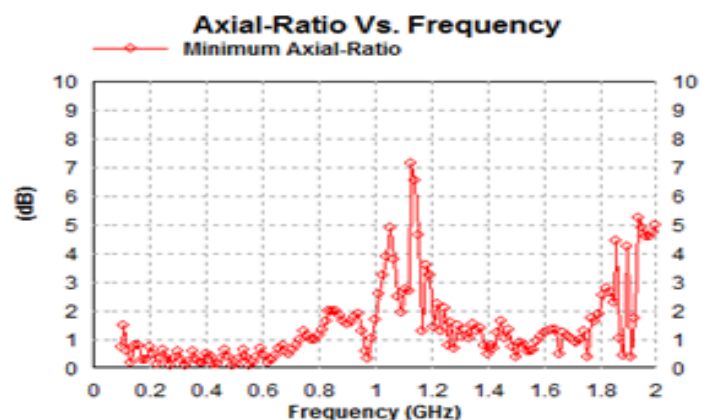

(f) Simulated Axial-Ratio of Designed Antenna

Figure-2 simulation result of- (a)simulated return loss of designed antenna (b) simulated gain of designed antenna (c) simulated directivity of designed antenna (d) simulated antenna efficiency of designed antenna (e) simulated radiating efficiency of designed antenna (f) simulated axial-ratio of designed antenna

Figure-3 shows the 3D radiation pattern and E-field of designed antenna at C.F. $1.337 \mathrm{GHz} \& 1.579 \mathrm{GHz}$ and figure-4 shows the 2D radiating pattern and E-field of designed antenna at C.F. $1.337 \& 1.579 \mathrm{GHz}$. The max. Axial-ratio of designed antenna is $7 \mathrm{dBi}$ this is shown in figure-2(f); so that the linear and circular polarization technique is improve the dual band antenna performance.

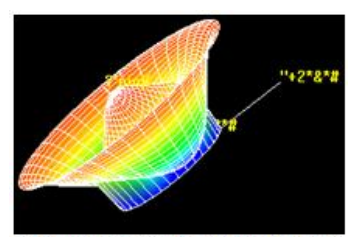

3D Pattern at C.F. 1.337 GHz (E-total)

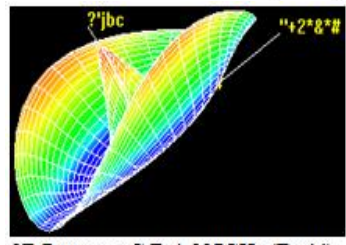

3D Pattern at C.F. 1.337GHz (E-phi)

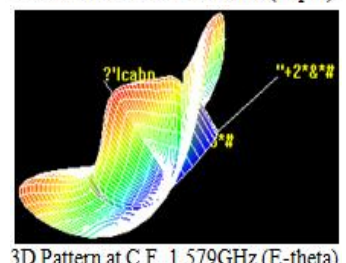

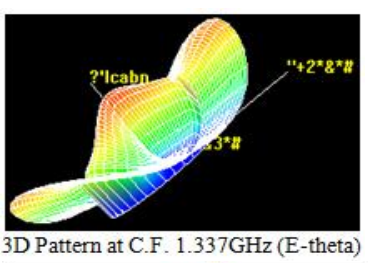

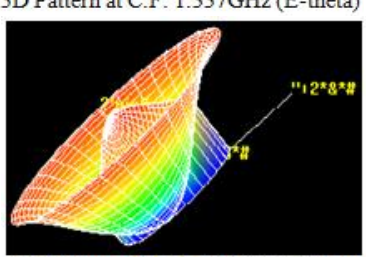

3D Pattern at C.F. $1.579 \mathrm{GHz}$ (E-total)

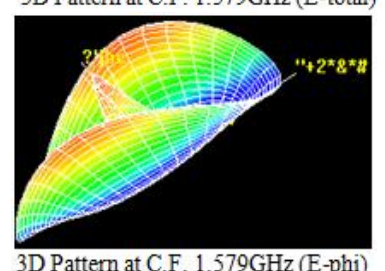

Figure-3 3D radiation pattern and E-field of designed antenna at C.F. 1.337GHz \& $1.579 \mathrm{GHz}$
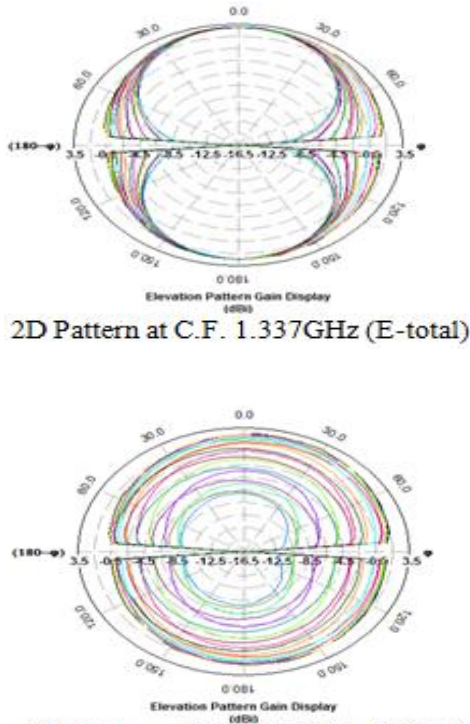

2D Pattern at C.F. 1.337GHz (E-theta)

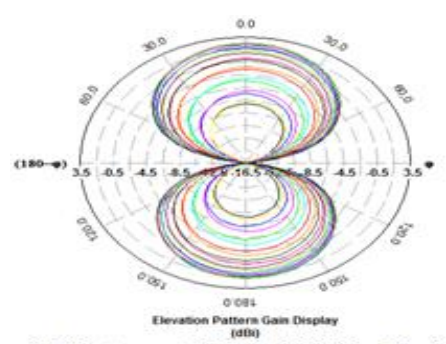

2D Pattern at C.F. $1.337 \mathrm{GHz}$ (E-phi)

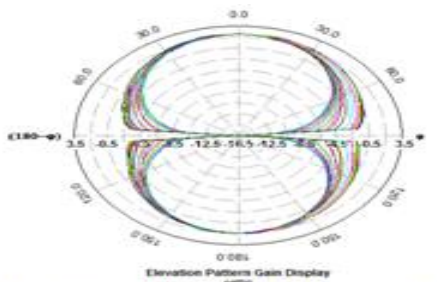

2D Pattern at C.F. $1.337 \mathrm{GHz}$ (E-left)

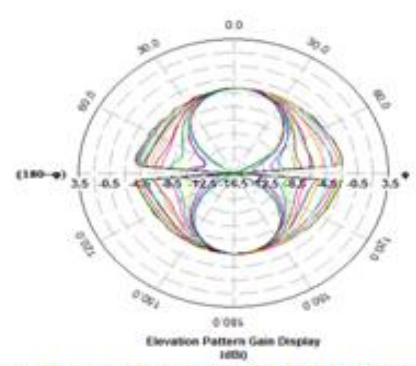

2D Pattern at C.F. $1.337 \mathrm{GHz}$ (E-right)

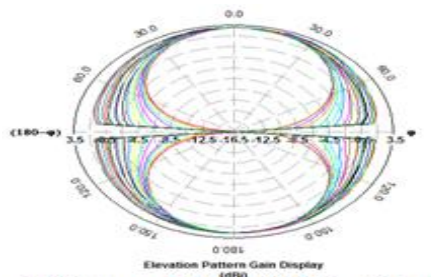

2D Pattern at C.F. $1.579 \mathrm{GHz}$ (E-total) 


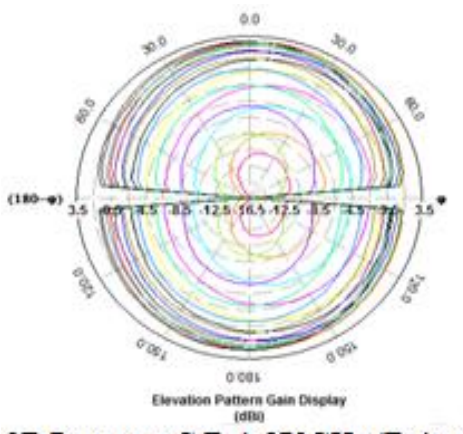

2D Pattern at C.F. $1.579 \mathrm{GHz}$ (E-theta)

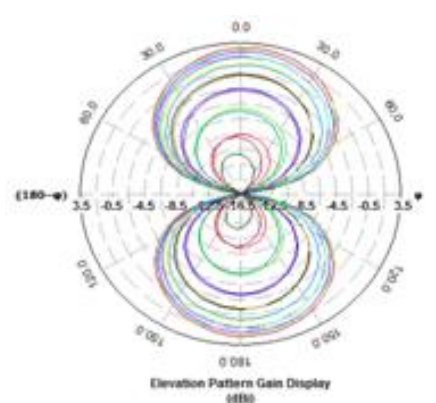

2D Pattern at C.F. $1.579 \mathrm{GHz}$ (E-phi)

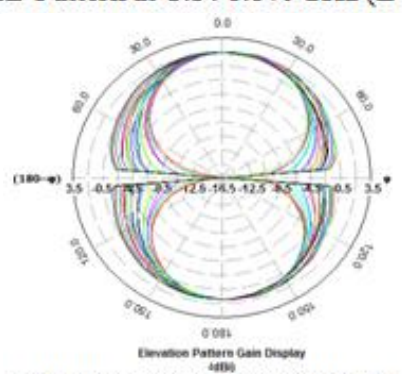

2D Pattern at C.F. $1.579 \mathrm{GHz}$ (E-left)

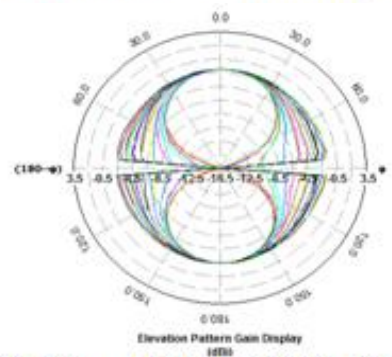

2D Pattern at C.F. $1.579 \mathrm{GHz}$ (E-right)

Figure-4 2D radiation pattern and E-field of designed antenna at C.F. $1.337 \mathrm{GHz} \& 1.579 \mathrm{GHz}$

\subsection{Antenna with slots cut in ground plane}

Figure- 5 shows the slots cut in ground plane and Table- 2 shows the dimension of ground and slots of designed antenna

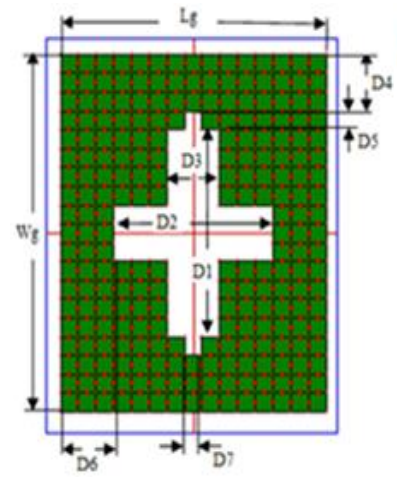

Table-2 dimension of ground plane and slots

\begin{tabular}{|c|c|}
\hline parameter & Length (in mm) \\
\hline Lg & 44.88 \\
\hline Wg & 55.07 \\
\hline D1 & 33 \\
\hline D2 & 27 \\
\hline D3 & 9 \\
\hline D4 & 9 \\
\hline D5 & 3 \\
\hline D6 & 9 \\
\hline D7 & 3 \\
\hline
\end{tabular}

Figure-5 slots cut in ground plane

\section{SIMULATION AND RESULT}

The simulation result of designed antenna without slots cut in ground plane we observe above in figure-2, 3, 4 after this result we cut the slots in ground plane and simulate again. In this result we get the antenna parameter is decreases due the reason of inductance and capacitance are developed. The result of antenna with slots cut in ground is shown in figure6.we observe this figure and achieve $3.06 \mathrm{dBi}$ and $2.97 \mathrm{dBi}$ gain for lower and upper band. The directivity of antenna is $4.3 \mathrm{dBi}$.

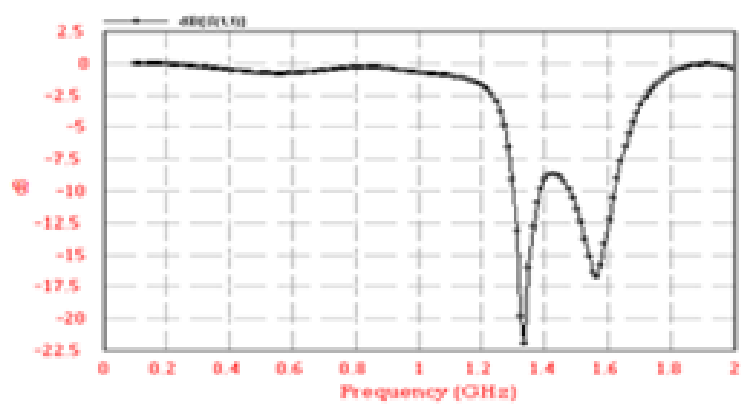

(a) Simulated retum loss of designed antenna

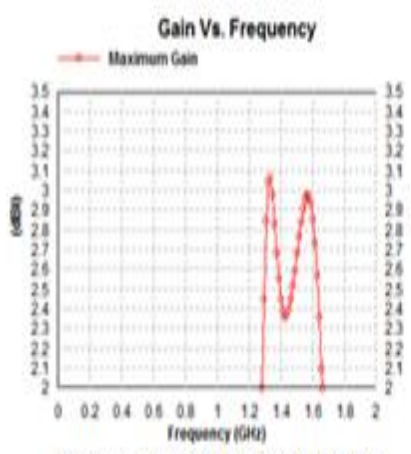

(b) Simulated gain of designed anteuna

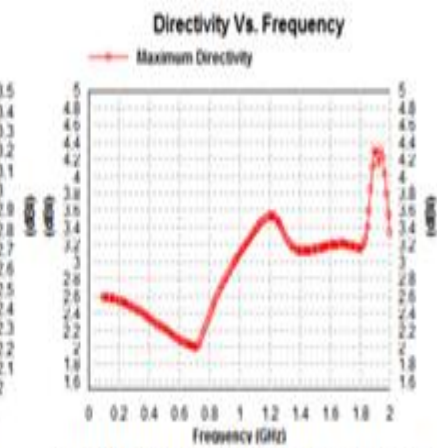

(c) simulated directirity of derigned antema

Figure-6 simulated result of designed antenna with slots cut in ground plane (a) simulated return loss of designed antenna (b) simulated gain of designed antenna (c)simulated directivity of designed antenna 


\section{COMPARISON OF SIMULATED RESULT OF DESIGNED ANTENNA WITHOUT SLOTS AND WITH SLOTS CUT IN GROUND}

\begin{tabular}{|c|c|c|}
\hline Parameter & $\begin{array}{c}\text { Result Without Slots Cut in Ground } \\
\text { Plane }\end{array}$ & $\begin{array}{c}\text { Result with Slots Cut in Ground } \\
\text { Plane }\end{array}$ \\
\hline VSWR & $<2$ & $<2$ \\
\hline B.W. & $\begin{array}{l}\text { 77MHz(LOWER BAND) } \\
\text { and } \\
\text { 153MHz(UPPER BAND) }\end{array}$ & $\begin{array}{l}\text { 77MHz(LOWER BAND) } \\
\text { and } \\
\text { 140MHz(UPPER BAND) }\end{array}$ \\
\hline GAIN & $\begin{array}{l}\text { 3.04dBi(LOWER BAND) } \\
\text { and } \\
\text { 3.12dBi(UPPER BAND) }\end{array}$ & $\begin{array}{l}\text { 3.06dBi(LOWER BAND) } \\
\text { and } \\
\text { 2.97dBi(UPPER BAND) }\end{array}$ \\
\hline DIRECTIVITY & $4.6 \mathrm{dBi}$ & $4.3 \mathrm{dBi}$ \\
\hline EFFICIENCY & $\begin{array}{c}\text { Max. 98.75\%(Antenna) } \\
\text { and } \\
\text { Max.99\%(Radiating) }\end{array}$ & $\begin{array}{c}\text { Max. 96.75\%(Antenna) } \\
\text { and } \\
\text { Max. 98.20\%(Radiating) }\end{array}$ \\
\hline
\end{tabular}

\section{VALIDATION}

As per graphically simulated result are suitable and we have validated our result by using vector analizer (N9923A)and see the sumulated and experimental result are approximatelly equal. The antenna is validated by ussing Agilent Network analyzer (N9923A). The hardware experimental result are as shown in figure-7.

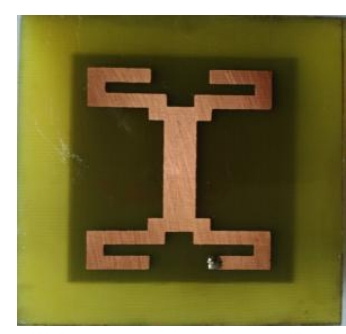

(a)

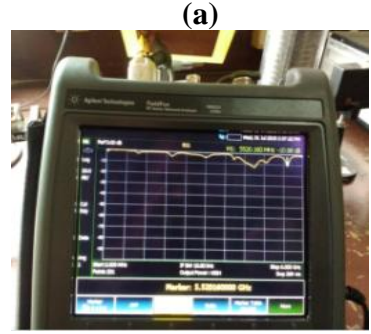

(c)

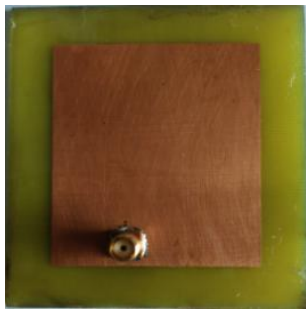

(b)

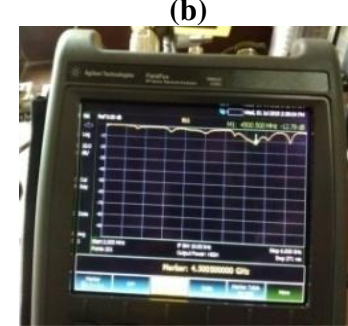

(d)

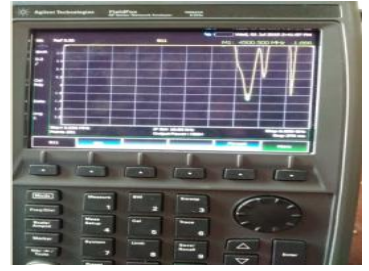

(e)

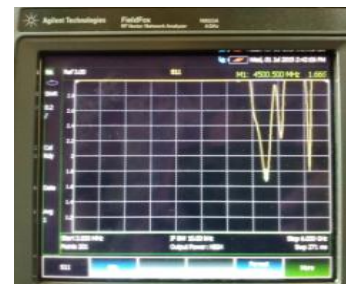

(f)

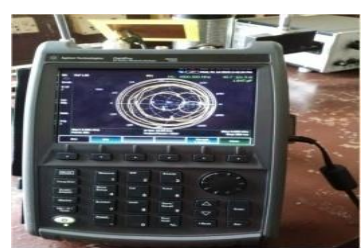

(g)

Figure-7 shows the experimental result of proposed antenna- (a) Top view of patch (b) Bottom view of ground (c) \& (d) Returnloss of proposed antenna (e) \& (f) VSWR (g) smith chart

\section{CONCLUSION}

In this paper the inverted $\mathrm{C}$ - shape microstrip patch antenna is designed for L-band application. The inverted C-shape is designed in patch and linear polarization technique is use for increasing the performance of designed antenna and to achieve a dual band. The presented antenna is capable \& suitable for GPS (global positioning system) carriers and satellite mobile phone application. We observe the simulated result and to get $3.04 \mathrm{dBi} \& 3.12 \mathrm{dBi}$ gain for lower and upper band .The bandwidth is $77 \mathrm{MHz}$ (lower band) and $153 \mathrm{MHz}$ (upper band). The designed antenna efficiency is max. 
$98.75 \%$ \& radiating efficiency is max. $99 \%$ and directivity is $4.6 \mathrm{dBi}$. If slots are cut in ground the antenna parameter is decreases due to the reason of inductance and capacitance. The designed antenna advantages of low profile, lower cost of fabrication \& easy manufacturing process.

\section{REFERENCES}

[1] Hsing-Yi chen and $\mathrm{Yu}$ Tao, "Performance Improvement of a U-Slot Patch Antenna Using a Dual-Band Frequency Selective Surface with Modified Jerusalem Cross Elements," IEEE Trans. Antennas Propag. Vol. 59, no. 9, pp. 3482-3486, sep.2011.

[2] Hattan F. Abutarboush, R. Nilavavalan, S.W. Cheung, Karim M. Nasr, Thomas Peter,Djuradj Budimir, and Hamed Al- Raweshidy, "A Reconfigurable Wideband and Multiband Antenna Using Dual-Patch Elements for Compact Wireless devices," IEEE Trans. Antennas Propag., vol. 60,no. 1,pp. 36-43, Jan. 2012.

[3] K. Ghorbani, and R.B. Waterhouse, "Dual Polarized Wide-Band Aperture Stacked Patch antennas," IEEE Trans. Antennas Propag. vol. 52, no. 8, pp.2171-2174, Aug. 2004.

[4] Tzung-Wern Chiou, and Kin-Lu Wong, "A Compact Dual-Band Dual-polarized Patch Antenna for 900/1800MHz Cellular Systems,'IEEE Trans. Antennas Propag., vol. 51, no.8, pp. 1936-1940, Aug. 2003.

[5] Alishir Moradi Kordalivand, and Tharck A.Rahman, "Broad Band Modified Rectangular Microstrip Patch Antenna Using Stepped Cut at Four Corners Method," Progress In Electromagnetic Research, vol. 137,599-619, 2013.

[6] C. Mahatthanajatuphat, P. Akkaraekthalin, S. Saleekaw, and M. Krairiksh, "A Bidirectional Multiband Antenna With Modified Fractal Slot Fed By CPW," Progress In Electromagnetics Research, PIER 95,59-72, 2009.

[7] W.-S. Chen, and B.Y. Lee," A Meander PDA Antenna for GSM/DCS/PCS/UMTS/WLAN Applications,"
Progress In Electromagnetics Research Letters, Vol.14, 101-109,2010.

[8] W.-J. Liao, S.-H. Chang, and L.K. Li, "A Compact Planar Multiband Antenna for Integrated Mobile Devices," Progress In Electromagnetics Research, vol.109, 1-16, 2010.

[9] J. Malik, and M.V. Kartikeyan, "Metamaterial Inspired patch Antenna with L-Shape Slot Loaded Ground Plane for Dual-Band (WiMax/WLAN) Applications," Progress In Electromagnetics Research Letters, vol. 31, 35-43, 2012.

[10] Y.-C. Lee, and J.S. Sun, "Compact Printed Slot Antenna for Wireless Dual-Band and multiband Operations," Progress In Eectromagnetics Research, PIER 88, 289305, 2008.

[11] Huda A. Majid, Mohamad K.A. Rahim, Mohamad R. Hamid , and Muhammad F. Ismail, "Frequency Reconfigurable Microstrip Patch-Slot Antenna With Directional radiation Pattern," Progress In Electromagnetics Research, vol. 144, 319-328, 2014.

[12] A.K. Arya, A. Patnaik, and M.V. Kartikeyan, "Microstrip Patch Antaenna With Skew-F Shaped DGS for Dual-Band Operation," progress In Electromagnetics Research M, vol. 19, 147-160, 2011.

[13] Dian Wang , Hang Wong, and Chi Hou Chan," Small Patch Antennas Incorporated With a Substrate Integrated Irregular Ground, "IEEE Trans. Antennas Propag., vol. 60, no.7,pp. 3096-3103, Jul. 2012.

[14] N.P. Asimakis, I.S. Karanasion, and N.K.Uzunoglu, "Non-Invasive Microwave Radiometric System for Intracranial Applications: A Study Using the Conformal L-Notch microstrip Patch antenna," Progress In Elecromagnetics Research, vol. 117, 83-101, 2011. 